(4)

\title{
Financial Crises and Adaptive Market Hypothesis: An Evidence from International Commodities traded at New York Stock Exchange
}

\author{
${ }^{a}$ Muhammad Naeem Shahid, ${ }^{\mathrm{b}}$ Khalid Latif, ${ }^{\mathrm{c}}$ Ghulam Mujtaba Chaudhary, ${ }^{\mathrm{d}}$ Shahid Adil \\ ${ }^{a} \mathrm{PhD}$ (Finance), Assistant Professor, Chinot Sub Campus, Government College University, Faisalabad \\ ${ }^{\mathrm{b}} \mathrm{PhD}$ (Finance) Assistant Professor, College of Commerce, Government College University, Faisalabad, Pakistan \\ ${ }^{c}$ PhD (Finance), Assistant Professor, University of Kotli, Azad Jammu and Kashmir. \\ ${ }^{\mathrm{d}} \mathrm{PhD}$ (Economics) Director/Additional Secretary, Punjab Economic Research Institute (PERI), Planning and \\ Development Board, Government of the Punjab, Lahore
}

\begin{tabular}{|c|c|}
\hline AR & \multirow{11}{*}{$\begin{array}{l}\text { ABSTRACT } \\
\text { This study evaluates the varying degree of predictability of commodities } \\
\text { return through empirical analysis of AMH (Adaptive Market } \\
\text { Hypothesis). We divide daily returns data (from } 1996 \text { to 2013) of } \\
\text { commodities indices (Gold, Metal, Oil\& Silver) into different crisis } \\
\text { periods. We subject all the subsamples to linear/nonlinear tests to reveal } \\
\text { how market efficiency (independency of returns) has behaved over time. } \\
\text { All the linear (except variance ratio) and nonlinear tests are evident that } \\
\text { commodity indices returns have been predictable (dependent) in some } \\
\text { crisis periods while unpredictable (dependence) in the others thus } \\
\text { consistent with the implication of AMH. Therefore, commodities markets } \\
\text { are adaptive markets. The findings suggest the behavior of commodities' } \\
\text { markets is best explained by AMH than conventional/traditional EMH } \\
\text { (Efficient Market Hypothesis). }\end{array}$} \\
\hline His & \\
\hline Hece & \\
\hline & \\
\hline Key & \\
\hline & \\
\hline Linea & \\
\hline Pres & \\
\hline & \\
\hline & \\
\hline & \\
\hline
\end{tabular}

(C) 2020 The authors. Published by SPCRD Global Publishing. This is an open access article under the Creative Commons Attribution-

NonCommercial 4.0

Corresponding author's email address: khalidlatif@gcuf.edu.pk

\section{Introduction}

In the field of economics and finance, one fundamental question is whether the prices of financial assets are foreseeable. In efficient market research (Fama, 1970) is pioneer, who explains efficient market as "A market in which prices always fully reflect all the available information". Similarly, EMH (efficient market hypotheses) states that the stock prices fully reflect all available and possible information about the stock being traded in the market thus under weak form of EMH no one is able to predict the prices and returns. Therefore, prices of assets follow martingale process and returns are characterized by MDS (martingale difference sequence). Studies of (Lim \& Brooks, 2008; Kim et al., 2011: Charles et. al, 2011) investigate the EMH in financial markets to test whether returns from assets follow MDS. Numerous studies have assessed the weak form efficiency of the EMH for commodities but these studies have not addressed the fluctuating degree of predictability of market efficiency except the study of (Ramirez et al., 2015) in which they employ a time varying approach with rolling window through nonlinear tests but the study is confined to nonlinear test and agriculture 
commodities only. But the current study aims to investigate the most popular commodity indices (gold, metal, oil \& silver) through both linear and nonlinear tests notably robust to heteroscedasticity and non-normality which are the two typical feature of financial assets' return (Charles et al., 2011). They employ moving sub-sample window approach to investigate in what way the levels/degree of predictability of returns vary/evolve over the time based on economic, financial and political events as well. Recent studies have documented that Asian financial crisis (Kim \& Shamsuddin, 2008; Lim et al., 2013), Dotcom crisis (Charles et al., 2011), Global Financial Crisis (Kim et al., 2011; Smith, 2012) and European Sovereign Debt crisis (Charles et al., 2011) cause market conditions to vary over time. The time-varying dependencies of financial time series are consistent with the idea as well as implications of Adaptive Market Hypothesis of (Lo, 2004) which is an amended form of Efficient Market Hypothesis of (Fama, 1970). Adaptive market hypothesis infers different impressive implications like profit opportunities may appear or vanish from one point in time to another due to changing levels of market conditions (cycles, bubbles, crises, crashes) and institutional factors. (Ho et al., 2014; Jawadi et al., 2014) investigate crisis period and infer that performance of Islamic indices is affected by varying degree of market conditions in crisis period especially GFC (Global Financial Crises). They further argue that these events have robust implications for market participants' psychology through their way they incorporate novel information to the security prices due to which serial correlation of series of return exhibit time variation. Arise of arbitrage opportunities from time to time in financial markets is another implication of $\mathrm{AMH}$. This implication infers that strategies aimed to exploit prevailing arbitrage opportunities may decline for some times and then again arise to profitability when conduce environmental conditions are available. Thus it is interesting to investigate the time varying nature of return predictability of commodity indices through AMH.

This study enhances the existing literature on adaptive market hypothesis in a number of ways. Firstly, this is the pioneer study which investigate the commodity indices in the context of adaptive market hypothesis to assess whether adaptive market hypothesis deliver a better representation of behavior of commodity return as compared to conventional efficient market hypothesis. Secondly, most of the early work on AMH investigate equity markets but there is no research that considers commodity markets which may provide a variety of findings. Thus in the current study we explore the varying degree (AMH) of commodity indices through different crises as according to the best of our knowledge only (Charles et al., 2011) study the time varying predictability of stock indices during crises through linear tests. Finally, most of the previous research work employs wide range of conventional linear models to determine the extent of linear predictability in financial assets' returns. But Amini et al. (2010) argue that some nonlinear predictability/dependency in financial time series may still be present which cannot be detected by using linear econometric models. In addition, if linear models reject the presence of linear predictability/dependence, the time series still can be evident of non-linear predictability/dependency. To the best of our knowledge, this research is the first of its nature to apply linear and non-linear models to explore linear as well as nonlinear serial dependencies to gauge the efficiency of commodity indices. The results of this study are consistent with the implications of AMH.

The remainder of this article is organized as follows. Subsequent segment presents related review of literature on efficiency of market under the umbrella of adaptive market hypothesis. The methodology and data are outlined in section 3 of the study. Section 4 describes the empirical results. Finally, findings and conclusions are presented in section 5 .

\section{Literature Review}

Numerous researchers in recent years have shifted their attention from detecting conventional static or absolute EMH to investigate the changing degree of efficiency of market over time which 
provides a way to AMH point of view (Lo, 2005; Ito \& Sugiyama, 2009; Kim, et al., 2011; AlvarezRamirez et al., 2012). Urquhart \& Hudson (2013) find same in the UK and US markets. In Asian Markets, Lim, et al. (2008); in Japanese Markets Noda (2012); and in Indian equity markets, Hiremath and Kumari (2014) have provided the similar findings. The identical evidence supporting AMH is found in foreign exchange markets (see Neely et al., 2009; Charles et al., 2012). From eighteen european contries, Smith (2012) finds evidence supporting AMH. To explore the commodities markets (international Coffee markets), Ramirez et al. (2015) apply nonlinear statistical models on returns from Colombian Arabica beans and identify the phases of market inefficiency and efficiency.

In order to understand the varying nature of behavior of returns, commodity return series are vital for investors, producers, policy makers and traders for better decision making (Karali \& Power, 2009). Historically, commodity return series have been modeled to predict the price volatilities AR (autoregressive), MA (moving average), ARIMA (Autoregressive integrated moving average) models and dynamic and transfer function analysis (Aradhyula \& Holt, 1988). Similarly in more recent time (Milas \& Otero, 2002) use STVECM as well as smooth transition vector error correction models while (Adrangi \& Chatrath, 2003; Benavides, 2004; Tansuchat et al., 2009) use GARCH model (generalized autoregressive heteroskedastic) to investigate the chaotic behavior of commodities' return. Similarly, (Ahti, 2009; Tejeda \& Goodwin, 2009) employ BDS test, correlation exponent, Lyapunov exponents test and neural networks to explore the chaotic behavior of returns from commodities. But in the current study we investigate the behavior of commodities under crisis through both linear and nonlinear tests.

S\&P index is investigated by Lo (2005) from year 1871 to 2003. By calculating first order autocorrelation, he finds cyclic patterns in market efficiency and observes market efficiency during 1950s. Furthermore, he suggests that changes in institutional ownership and dynamics of investors' behavior are the main cause of variation in the levels of market efficiency. Foreign exchange market is investigated by Neely et al. (2009) over the period of 1970s-1980s. By taking excess returns from trading rules, the researchers observe that over the time the trading rules have declined and supporting $\mathrm{AMH}$. Lo (2005) reports that trading strategies decline in adaptive markets and then again result in a substantial profitability. Lim et al. (2008) investigate efficiency of stock markets of developed and developing countries. In order to scrutinize the evolutionary tends, they employ portmanteau bicorrelation test statistic and observe episodes of market inefficiency and efficiency over the sample period. By using moving-average rules approaches, Todea et al (2009) investigate the levels of profits during the period 1997 to 2008 in six security markets in Asian countries. They find that profit opportunity goes under periods of linear and no linear correlations. By employing time-varying autocorrelation, Ito \& Sugiyama (2009) investigate S\&P 500 index. By using monthly returns from the index, they observe the variations in the levels of market efficiency because market remained inefficient during 1980s, and again efficient in the late 1990s period. 'Dow Jones Industrial Average index (DJIA)' is investigated by Kim et al. (2011)1 from year 1900 to 2009. The researchers observe that predictability of returns is based on varying market conditions thus supporting AMH (Adaptive market hypothesis). During market crashes they find no statistically significant prediction of profits and claim that levels of uncertainty determine predictability of returns. They further argue that during the periods of uncertainty (economic distresses as well as political crises) of predictability, the stock returns are likely to be anticipated.

Over the period of 2000 to 2009, Martingale hypothesis is examined by Smith (2012) in fifteen

1They applied generalized spectral test, variance ratio (VR-test ) \& autocorrelation tests. 
European Stock markets2 to study the AMH. Moreover, equity markets from developed countries (Greece, Portugal \& UK) are also included in the sample. By using VR-model and rolling window analysis he captures episodes of efficiency and inefficiency in equity markets of most of the European markets hence supporting AMH. He finds efficiency in equity markets of United Kingdom, Turkey, Poland and Hungary while inefficiency in Estonia, Malta and Ukraine. In order to find whether AMH delivers better depiction of behavior of emerging equity markets of India, , Hiremath and Kumari (2014) employ linear as well as nonlinear models on daily returns over the period from 1991 to 2013. The researchers find that equity markets of India are becoming efficient. Linear dependencies demonstrate the cyclic patterns in stock returns which depict that Indian stock markets switch in episodes of predictability and no predictability. On the other hand, nonlinear prediction of returns with narrowing magnitude is exposed by nonlinear tests over the sample period.

By using fluctuation analysis over a sample period of 1929 to 2014, Rodriguez (2014) examines yearly, quarterly, monthly, weekly and daily returns from DJIA. The study finds that inter-days and intra-day returns show a stronger serial correlation as compared to overnight returns. He finds no uniform patterns in efficiency of DJIA which supports AMH. Urquhart et al. (2015) suggest that AMH infers that trading rules are effective and beneficial for a short term period only. As the behavior of markets and investors adapt, the predictive power of the trading rules also declines. From year 19872013, they investigate moving average rule (MA) in DJIA, FT 30 \& TOPIX from US, UK and Japan respectively and find that predictive power of the trading rules has declines in all the three markets. Furthermore, they assert that after 1987 these three markets react to new buy or sell signals a day before those signals are appeared. Based on expectation from those signals, investors can earn superior profits by making trading strategies. "Hence, trading on anticipated signals establishes a reasonable explanation of price responses to future, one-day-ahead new signals, and thus consistent with the Adaptive Market Hypothesis". Recently, Noda (2016) finds level of predictability (market inefficiency) fluctuates over time and verifies the AMH in Japanese equity markets. Ito et al. (2016) investigate US equity markets by developing a "non-Bayesian time varying model" and assert that US equity markets have tendency to evolve over time and verify the AMH. Sensory et al. (2015) employ Lo-MacKinlay variance ratio test and assert that global financial crises have an adverse effect upon the levels of market efficiency. The findings of all aforementioned studies show that market efficiency fluctuates in episodic manner and goes under significant and no significant predictability therefore supporting AMH of (Lo, 2004).

\section{Methodology}

The Weak-form efficient market hypothesis states that historical information related to trading of securities is fully captured by the security prices and hence prices are not predictable. This is because the information moves randomly in the market and any kind of prediction is fruitless for the investors. In order to investigate how market efficiency (predictability of return) varies depending upon different major financial crises, we divide our data set into different sub-samples like (i) from June 1997 to January 1998 (Asian Financial Crisis); (ii) from March 2000 to October 2002 (Dotcom Crisis); (iii) from July 2007 to June 2009 (Global Financial Crisis); and (iv) from December 2009 to December 2012 (European Sovereign Debt Crisis). Each sub-sample provides sufficient time series observations to produce adequate and robust results to examine the time variant behavior of returns from commodities over time. In an adaptive markets, the behavior of commodities returns goes under the episodes of dependencies (predictability/market inefficiency) and episodes of independencies (unpredictability/market efficiency). Therefore, we apply series of linear and non-linear models to

2Markets investigated in the research are based in the Ukraine, Slovenia, Turkey, the Slovak Republic, Romania, Russia, Malta, Poland, Lithuania, Latvia, Hungary, Iceland, Estonia, Croatia, Czech Republic. 


\section{Review of Economics and Development Studies, Vol. 6 (1) 2020, $\quad 67-81$}

investigate the fluctuating behavior of commodities returns. From linear models we first apply autocorrelation test having null hypothesis "random walk process or no correlation". Secondly we apply runs test, null hypothesis of this test implies "serial independence of returns" (Wald \& Wolfowitz, 1940). Finally, variance ratio (VR) test is employed having null hypothesis as "price processes follow a random walk" (Lo \& MacKinlay, 1988).

The aforementioned tests portrays different conventional linear models to detect linear dependence in commodity returns. Amini et al. (2010) describe that security returns also exhibit nonlinear dependencies (predictability) and conventional linear tests may not detect the phenomenon. If linear tests reject the existence of linear dependencies, the nonlinear predictability still can be present in series of commodities returns. The presence of nonlinear prediction has gained significant attentions in the former studies (see Hiremath \& Kamaiah, 2010; Alagidede, 2011; Caraiani, 2012; Urquhart, 2013; Lim \& Hooy, 2013; Urquhart \& Hudson, 2013; Ghazani \& Araghi, 2014; Ramirez et al., 2015;). As the data generating process is innately non-linear, therefore, linear models are not solely consistent to investigate the behavior of commodities returns.

Alharbi (2009) describes, in order to investigate the higher levels of dependencies in the time series, non-linear models are more conventional than linear tests. Therefore, first we apply BDS nonparametric test as suggested by (Brock et al., 1996) to gauge the predictability of non-linear returns where null hypothesis of BDS implies data generating process is i.i.d3. The embedding dimensions and metric bounds up to 5 (to a proportion of the standard deviation of the returns) are selected in the current studies for BDS test as suggested by in literature (Patterson \& Ashley, 2000). "Secondly, we apply Lagrange Multiplier test4" proposed by (Engle, 1982) to detect ARCH disturbances bearing asymptotically distribution as null hypothesis. A time series is supposed to be evident of ARCH/GARCH effects or nonlinear-dependence if series rejects the null hypothesis. Thirdly, a multipurpose test is applied named as non-linear McLeod and Li test (McLeod \& Li, 1983)5 which investigates whether the series of returns having a non-zero autocorrelation function or not. The null hypothesis of the test implies no ARCH effects between lag1 and lag k returns meanings that there is no serial dependency among returns. If this null hypothesis is rejected, then a time series is supposed to be evident of $\mathrm{ARCH} / \mathrm{GARCH}$ effects. Lastly, to observe the "quadratic-serial dependence" in the time series data6, (Tsay, 1986) proposes Tsay test to measure this pattern.

All the linear and nonlinear test are applied on sub-samples based on crises periods selected in this study for commodities (Gold, metal, oil \& silver). Dependence in this study is investigated from statistical viewpoint. Fama (1965) reports that it is essential to investigate the predictability (dependency of returns) from statistical point of view because the levels of predictability may be too small to facilitate profitable trading due to transaction cost. The current study ignores the extent to which degree of predictability enables the investors to earn profit subjective to major problems in estimate of real historical-trading costs.

\subsection{Data}

For the estimation of data, we employ the both linear as well as non-linear empirical tests on daily returns of Commodity Indices (Gold, metal, oil \& silver) during crisis periods. The returns are

\footnotetext{
3 "Alternative hypothesis is an indication that the model is misspecified (Brock, Scheinkman, LeBaron, \& Dechert, A Test for Independence Based on the Correlation Dimention, 1996)".

4 Against GARCH alternatives, Engle suggest the Lagrange Multiplier test to identify ARCH effects which is more suitable (Bollerslev, 1986).

5 To identify ARCH effects, (McLeod \& Li, 1983) proposes this test which is developed on the suggestions of (Granger \& Anderson, 1978), recommends the said test to measure the ARCH-effects.

6 "Tsay-test (Tsay, 1986) is a generalization of (Keenan, 1985) test".
} 
calculated as under;

$$
r_{t}=\left[\ln \left(P_{t}\right)-\ln \left(P_{t-1}\right)\right] \times 100
$$

Where, $\ln \left(\mathrm{P}_{\mathrm{t}}\right)$ is the natural logarithm of the Commodity Index at time $\mathrm{t}$, while $\ln \left(\mathrm{P}_{\mathrm{t}-1}\right)$ depicts the natural logarithm of the Commodity Index at $t-1$. Descriptive statistics for Commodity Indices are reported in Table-1. Average daily Commodity Indices returns for Gold and Metal are positive in all crisis periods except Asian crisis period. Similarly average daily returns for silver are positive in all crisis periods except Dotcom crisis period which indicate that magnitude of extreme positive average returns is greater than the magnitude of extreme negative returns (for gold, metal \& silver). Average returns for Oil display different behavior where the magnitude of extreme negative average returns is greater than the magnitude of extreme positive returns. Return series of all commodities are evident of non-normality as gold and metal show negative skewness in Asian and ESDC crises while positive in Dotcom and GFC crises. Oil and silver show negative skewness in all the crises periods except Asian crisis period. All the commodities employing a leptokurtic series as all the series are evident of excess kurtosis. For normality test, the Jarque-Bera test statistics documented the statistically significance at 1\% level, which shows that the Commodity Indices returns are non-normally distributed.

\section{Table1 Descriptive Statistics of Commodities (Gold, Metal, Oil \& Silver) under} different crises periods. Where "a" depicts $1 \%$ level of significance

\begin{tabular}{|l|l|l|l|l|l|l|l|l|l|l|}
\hline Crisis & $\mathrm{N}$ & Mean & Median & Maximum & Minimum & Std. Dev. & Skewness & Kurtosis & Jarque-Bera \\
\hline \multicolumn{9}{|c|}{ Panel A: GOLD } \\
\hline Asian & 175 & -0.0753 & -0.10145 & 3.095829 & -5.08368 & 0.923716 & $-0.6094 \mathrm{a}$ & $7.7958 \mathrm{a}$ & $178.545 \mathrm{a}$ \\
\hline Dotcom & 697 & 0.011334 & 0.000000 & 6.575366 & -3.43872 & 0.832869 & $1.07835 \mathrm{a}$ & $10.9058 \mathrm{a}$ & $1950.16 \mathrm{a}$ \\
\hline ESDC & 805 & 0.043333 & 0.072425 & 3.649984 & -6.02906 & 1.119549 & $-0.8286 \mathrm{a}$ & $6.3572 \mathrm{a}$ & $470.186 \mathrm{a}$ \\
\hline GFC & 522 & 0.067821 & 0.022693 & 8.590126 & -6.03735 & 1.656648 & $0.2552 \mathrm{a}$ & $5.6612 \mathrm{a}$ & $159.705 \mathrm{a}$ \\
\hline & Panel B: METAL \\
\hline Asian & 175 & -0.04484 & -0.05979 & 2.893866 & -4.70066 & 0.911980 & $-0.5031 \mathrm{a}$ & $6.6181 \mathrm{a}$ & $102.840 \mathrm{a}$ \\
\hline Dotcom & 697 & 0.010401 & 0.000000 & 6.359632 & -3.17032 & 0.794419 & $1.004 \mathrm{a}$ & $10.362 \mathrm{a}$ & $1691.408 \mathrm{a}$ \\
\hline ESDC & 805 & 0.045258 & 0.080108 & 3.760591 & -7.91834 & 1.244303 & $-0.950 \mathrm{a}$ & $6.8107 \mathrm{a}$ & $608.383 \mathrm{a}$ \\
\hline GFC & 522 & 0.062285 & 0.065317 & 8.758968 & -6.27334 & 1.721034 & $0.2027 \mathrm{a}$ & $5.7022 \mathrm{a}$ & $162.395 \mathrm{a}$ \\
\hline \multicolumn{8}{|c|}{} \\
\hline Asian & Panel C: OIL & 175 & -0.11049 & 0.000000 & 6.626127 & -4.1886 & 1.620369 & 0.1612 & $4.405 \mathrm{a}$ & $15.155 \mathrm{a}$ \\
\hline Dotcom & 697 & -0.016 & 0.000000 & 8.072207 & -16.542 & 2.404796 & $-0.7133 \mathrm{a}$ & $7.216 \mathrm{a}$ & $575.452 \mathrm{a}$ \\
\hline ESDC & 805 & 0.021416 & 0.017099 & 8.946654 & -9.03834 & 1.804622 & $-0.2192 \mathrm{a}$ & $5.143 \mathrm{a}$ & $160.527 \mathrm{a}$ \\
\hline GFC & 522 & -0.00215 & 0.000000 & 13.34145 & -13.0654 & 3.207857 & -0.1623 & $5.161 \mathrm{a}$ & $103.936 \mathrm{a}$ \\
\hline & Panel D: SILVER \\
\hline Asian & 175 & 0.154371 & 0.053628 & 7.546039 & -6.43653 & 1.735743 & $0.2729 \mathrm{a}$ & $5.908 \mathrm{a}$ & $63.839 \mathrm{a}$ \\
\hline Dotcom & 697 & -0.01802 & 0.000000 & 5.902624 & -4.52938 & 0.995644 & $-0.2037 \mathrm{a}$ & $6.236 \mathrm{a}$ & $309.077 \mathrm{a}$ \\
\hline ESDC & 805 & 0.060822 & 0.138893 & 6.825158 & -19.4889 & 2.327827 & $-1.2741 \mathrm{a}$ & $10.130 \mathrm{a}$ & $1923.32 \mathrm{a}$ \\
\hline GFC & 522 & 0.016572 & 0.173242 & 12.47068 & -13.8343 & 2.754893 & $-0.3961 \mathrm{a}$ & $6.865 \mathrm{a}$ & $338.623 \mathrm{a}$ \\
\hline
\end{tabular}

\section{Results}

\subsection{Results of Linear Tests}

Table 2 presents the results of Autocorrelation test for sub-samples (crises) up to five lags. Coefficients of Gold \& Silver indices exhibit insignificant and negative first order autocorrelation during Asian crisis showing returns remain unpredictable (market efficiency). The behavior of Gold \& Silver indices then reverses and autocorrelation is highly significant during Dotcom and European Sovereign Debt crisis showing evidence of return predictability (market inefficiency) on the basis of historical data. The behavior again reverses and unpredictable in Global financial crises showing predictability of Gold \& silver returns goes under periods of predictability and no predictability (evidence of AMH). 


\section{Review of Economics and Development Studies, Vol. 6 (1) 2020, $\quad 67-81$}

Metal index generates significant coefficients for first three crises sub-samples (Asian crisis, Dotcom crisis \& European Sovereign Debt crisis) indicating returns from Metal index remains predictable (market inefficiency) over the period of all three crisis as first order autocorrelation is highly significant at all the lags. The behavior then reverses and returns are unpredictable (market efficiency) in Global financial crisis as coefficient generates insignificant first order autocorrelation at all the lags. Oil index shows inverse behavior to Metal index as Oil index generates insignificant coefficients for first three crises sub-samples (Asian crisis, Dotcom crisis \& European Sovereign Debt crisis) indicating returns from oil index remains unpredictable (market efficiency) over the period of all three crisis as first order autocorrelation is highly insignificant at all the lags. The behavior then reverses and returns are predictable (market inefficiency) in Global financial crisis as coefficient generates significant first order autocorrelation at all the lags. It is clear from autocorrelation test that AMH is best elucidation of behavior of all indices as the indices have gone through episodes of non-predictability (independency) and predictability (dependency) over time.

\section{Figure 1 Log price and log returns of Commodities (Gold, Metal, Oil \& Silver) over the specified sample period}

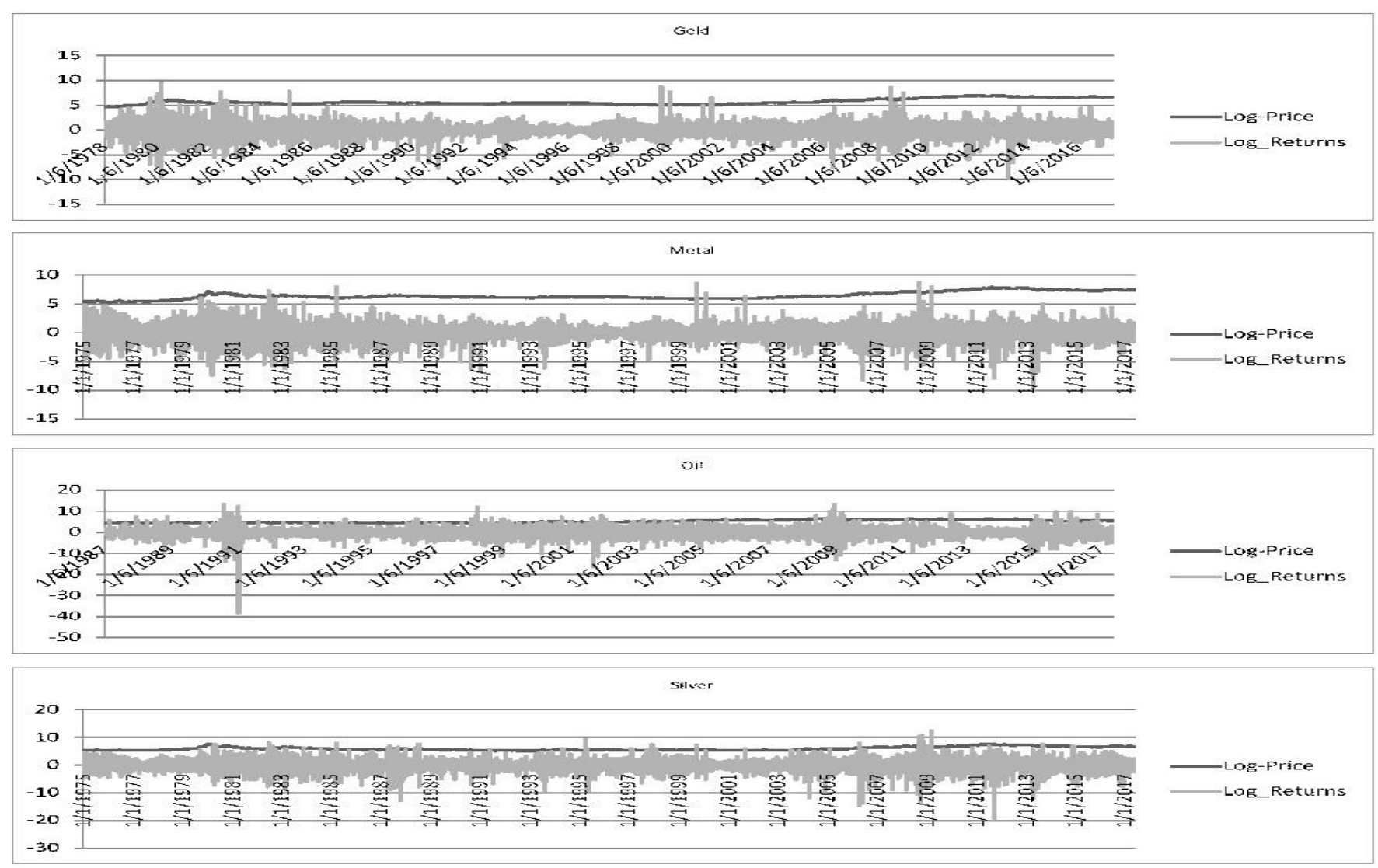

Source: Elaboration of data collected from Yahoo-Finance through R-Statistical Package

Table 2 also reports the output of runs test and reveals Gold index has independent behavior as the test-statistic of runs test is insignificant (no return predictability) in Asian crisis. The next two subsamples of crisis (Dotcom crisis and European Sovereign debt crisis) exhibit significant linear dependence as $\mathrm{z}$ - values are highly significant (returns predictability/market inefficiency). The behavior then again reverses in the Global financial crisis and is evident of no linear dependency as coefficient of $\mathrm{z}$ - value is insignificant (period of market efficiency). The empirical results of runs model show that Gold index has gone via episodes of predictability (dependency) and episodes of no predictability (independency) over time, thus $\mathrm{AMH}$ provides better description of returns in commodities markets. Metal index generates significant $\mathrm{z}$ - valuesfor first three crises sub-samples 
(Asian crisis, Dotcom crisis \& European Sovereign Debt crisis) indicating returns from Metal index remains inefficient (linear dependency) over the period of all three crisis. The behavior then reverses and returns are efficient (no linear dependency) in Global financial crisis as coefficient generates insignificant $\mathrm{z}$ - values. Oil index generates insignificant $\mathrm{z}-$ values in all the crises periods thus indicating market efficiency. Silver generates significant $\mathrm{z}$ - values (linear dependence) during Asian crisis, the behavior then reverses and index returns are unpredictable during Dotcom crisis as $\mathrm{z}-$ value is insignificant. The returns becomes again predictable and market becomes inefficient in European Sovereign Debt crisis. The behavior reverses during Global financial crisis as returns have no non-linear dependence (market efficiency) as $\mathrm{z}$ - value is insignificant. Runs test reveals that except Oil index, all the indices go under periods of significant dependency and periods of independency over the periods of crises thus AMH is best to explain the behavior of commodities indices than EMH.

Table 3 presents the results for variance ratio test for all commodities during four crises. We find mean reversions between returns of all the commodities during crises periods as all four $k^{\prime} s$ reveal statistically significant test statistics (at $1 \%$ ) which is less than 1 . The results reveal that returns of all the commodities are predictable during crises periods and commodities markets are inefficient.

Table 2 Output of Linear Autocorrelation test and non-parametric runs test results for commodities (Gold, Metal, Oil \& Silver) under crises. First column represents different crises. Columns 3 to 7 show depicts the Autocorrelation coefficient

Lags 1 to 5 while columns 8 to 13 show the results of non-parametric runs

test.

Where "a" depicts $1 \%$ level of significance, while " $b$ " represents $5 \%$ and

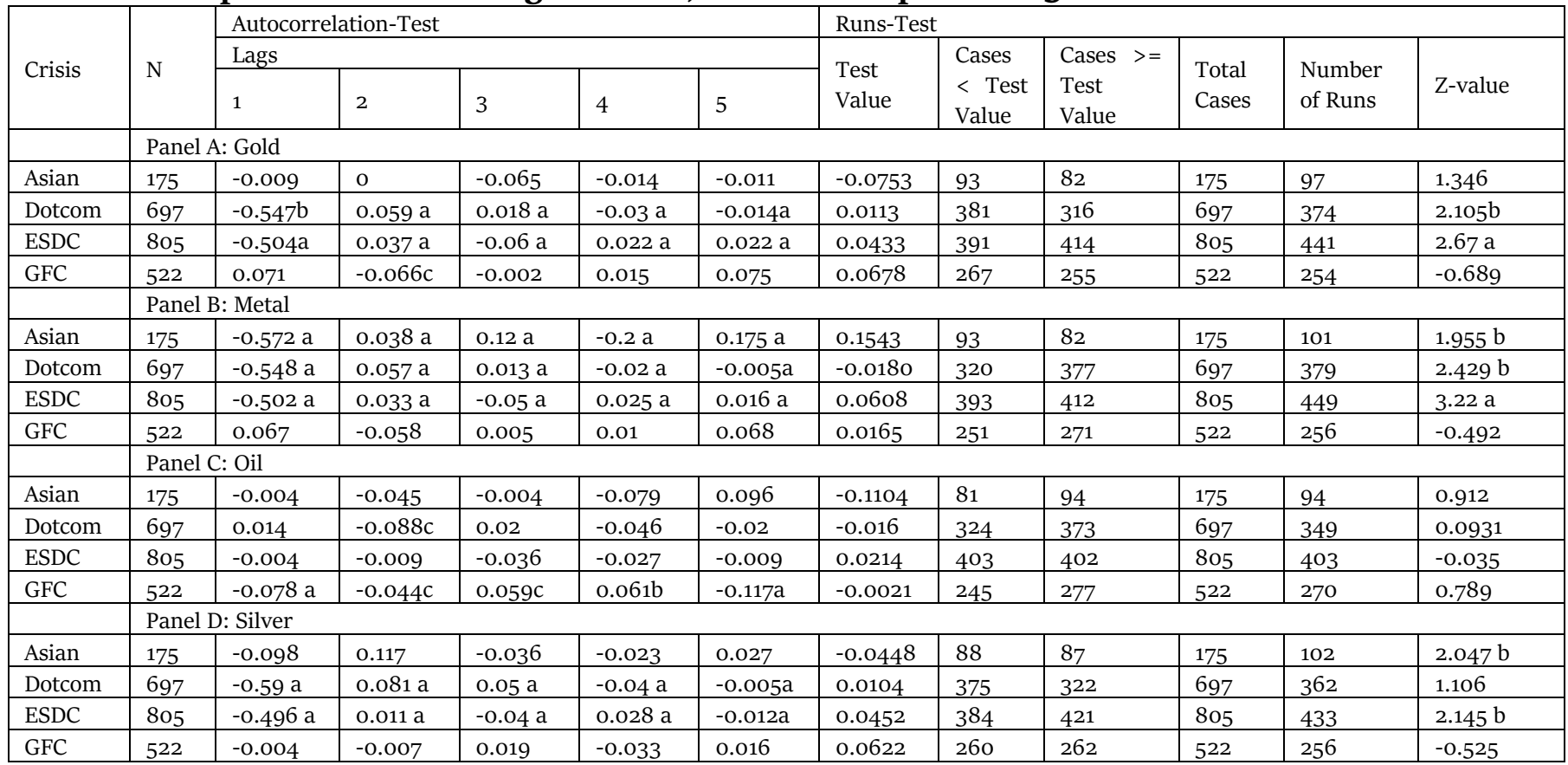

Figure 2 Statistics of linear test employed for Commodities (Gold, Metal, Oil \& Silver).

RUNS stands for z-statistic of the runs test. For lag 1, autocorrelation statistic 

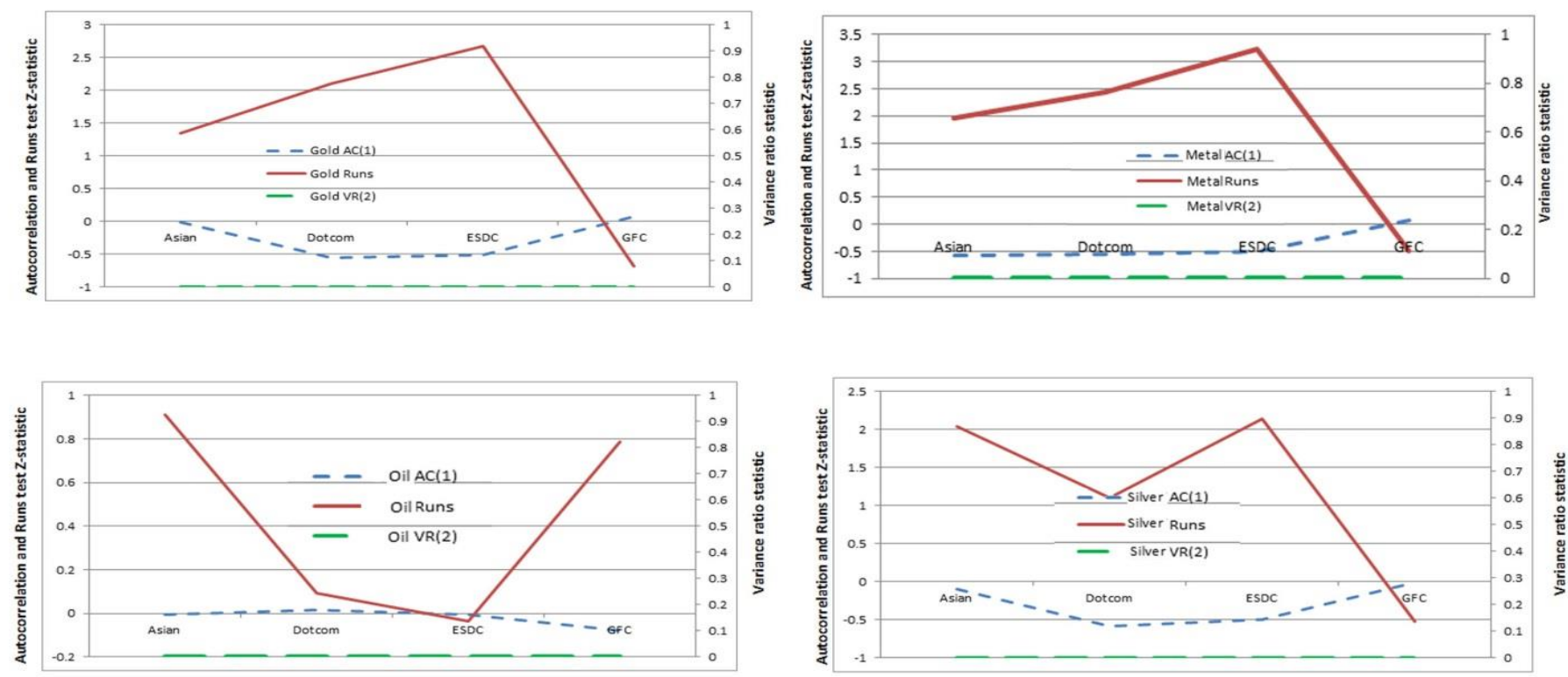

Figure 3 Statistics of non-linear test employed for Commodities (Gold, Metal, Oil \& Silver). BDS $(3,1)$ stands for dimension 3 along with $1 \sigma$ embedding dimension for BDS test, lags 1,2,3,4 and 5, LM(5) represents Engle-LagRange Multiplier tests statistics, while, Tsay(5) stands return predictability up to lag 5 for Tsay test
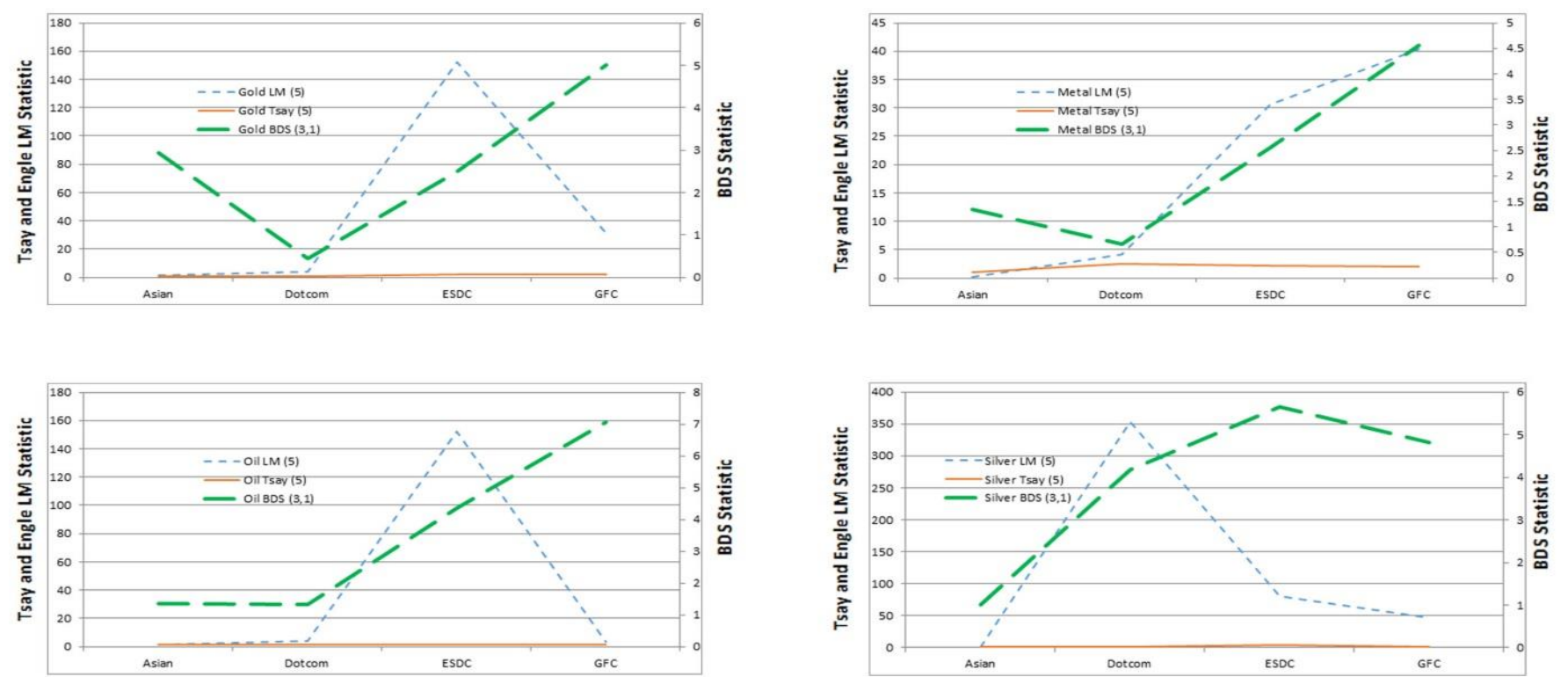

\subsection{Results of Nonlinear Tests}

Tables 4 \& 5 report the Nonlinear Empirical results for Gold, Metal, Oil and Silver, while Table 3 presents Ljung-Box test statistics before and after implementing AR filter which shows the presence of temporal linear structure (significant autocorrelation up to 5, 10, 15 and 20 lags at $1 \%$ level of significance) in all the series during all four crises periods. Thus in order to explore non-linear dependence in indices returns the linear dependence must be removed. For the reason, a pre-whitening AR-model can aid as a filter to eliminate any residual linear dependence and assist to investigate the nonlinear dependency in the commodity returns. We estimate and present AR-models in table 3. It is clear from the table that linear dependency (autocorrelation) is successfully removed (after AR filter) 
from the commodities returns as the series possess no statistically significant correlation up to 20 lags during all four crises. The filtered returns then subjected to nonlinear tests (BDS test, Engle LM, McLeod Li test and Tsay-test as discussed in the methodology) to detect nonlinear dependency. The Gold index show similar results at Engle LM, McLeod Li and Tsay test as the tests statistics reveals insignificant nonlinear dependence (indication of market efficiency) during Asian and Dotcom crises.

Table 3 Columns 3 to 6 shows the results of Variance ratio (VR) for sample commodities panels (Gold, Metal, Oil \& Silver) in Crises periods (where $\mathrm{k}=2,4,8$ \& 16). Ljung-Box Q (LBQ) test results before fitting An AR-model (presented in columns 7 to 10) and after fitting an AR-model (presented in columns 12 \&13). Where "a" depicts $1 \%$ level of significance, while "b" represents 5\% and "c" shows $10 \%$.

Table 4 presents results of nonlinear tests for commodities (Gold, Metal, Oil \& Silver). Columns 3 to 6 and 7 to 10 present test statistics ( at lags 5,10,15 \& 20) for Engle Lagrange Multiplier and Tsay tests respectively in sub as well as in full-samples. First column represents dates (Starting \& ending). Columns 11 to 14 focus on the tests statistics Qr (McLeod Li test) to examine the null-hypothesis that "increments are i.i.d.", where serial dependency of returns is represented by "D" while independence of returns is represented by "I". ). Where "a" depicts $1 \%$ level of significance, while "b" represents $5 \%$ and "c" shows $10 \%$.

Table 3

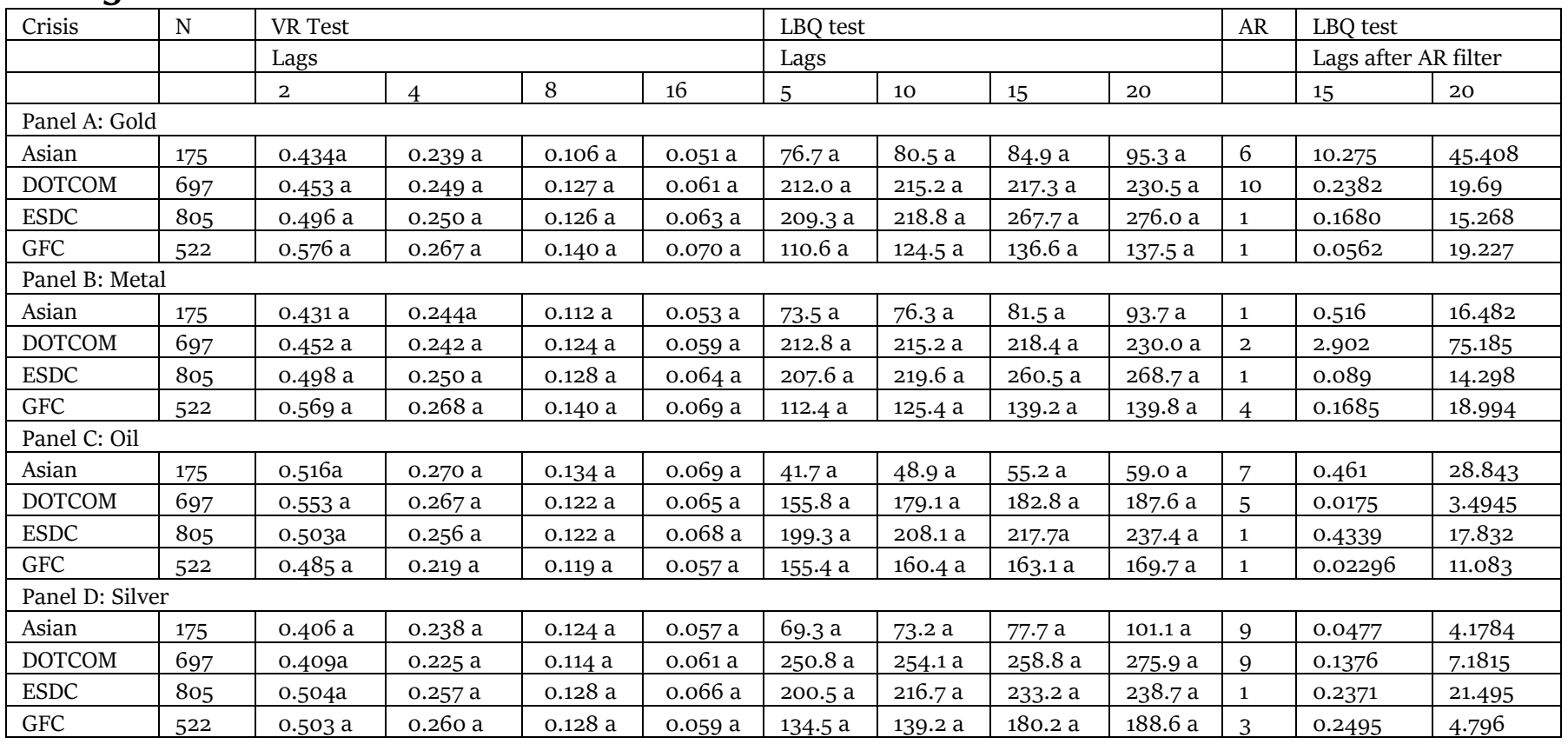

\section{Table 4}

\begin{tabular}{|c|c|c|c|c|c|c|c|c|c|c|c|c|c|c|}
\hline \multirow{2}{*}{ Crisis } & \multirow{2}{*}{$\mathrm{N}$} & \multirow{2}{*}{ AR } & \multicolumn{4}{|c|}{ Engle LM Test-Statistics } & \multicolumn{4}{|c|}{ TSAY Test-Statistics } & \multicolumn{3}{|c|}{$\begin{array}{l}\text { McLeod-Li } \\
\text { Statistics }\end{array}$} & \\
\hline & & & 5 & 10 & 15 & 20 & 5 & 10 & 15 & 20 & 5 & 10 & 15 & 20 \\
\hline & \multicolumn{14}{|c|}{ Panel A: Gold } \\
\hline Asian & 175 & 6 & 1.271 & 1.474 & 1.81 & 5.297 & 1.023 & 0.701 & $1.562 \mathrm{C}$ & 1.003 & $\mathrm{I}$ & $\mathrm{I}$ & $\mathrm{I}$ & $\mathrm{I}$ \\
\hline GFC & 522 & 1 & $31.4 \mathrm{~b}$ & $29.58 \mathrm{a}$ & $34.112 \mathrm{a}$ & $34.37 \mathrm{~b}$ & $2.165 \mathrm{a}$ & $1.405 \mathrm{~b}$ & $1.862 \mathrm{a}$ & $1.918 \mathrm{a}$ & $\mathrm{D}$ & $\mathrm{D}$ & $\mathrm{D}$ & $\mathrm{D}$ \\
\hline
\end{tabular}


Review of Economics and Development Studies, Vol. 6 (1) 2020, $\quad 67-81$

\begin{tabular}{|c|c|c|c|c|c|c|c|c|c|c|c|c|c|c|}
\hline & \multicolumn{14}{|c|}{ Panel B: Metal } \\
\hline Asian & 175 & 1 & 0.234 & 0.459 & 0.748 & 0.926 & 1.062 & 0.645 & 0.8223 & 0.783 & $\mathrm{I}$ & I & I & I \\
\hline ESDC & 805 & 1 & $30.54 a$ & 81.78 & $83.73 a$ & $86.64 \mathrm{a}$ & $2.173 \mathrm{a}$ & $2.008 \mathrm{a}$ & $1.631 \mathrm{a}$ & $1.695 \mathrm{a}$ & $\mathrm{D}$ & $\mathrm{D}$ & $\mathrm{D}$ & $\mathrm{D}$ \\
\hline & \multicolumn{14}{|c|}{ Panel C: Oil } \\
\hline Asian & 175 & 7 & 1.271 & 1.474 & 1.81 & 5.297 & $1.65 \mathrm{C}$ & $1.477 \mathrm{~b}$ & $2.08 \mathrm{~b}$ & $1.78 \mathrm{~b}$ & $\mathrm{I}$ & I & I & I \\
\hline Dotcom & 697 & 5 & 3.826 & 12.43 & 13.02 & 18.1 & $1.56 \mathrm{c}$ & 1.221 & 1.173 & 1.106 & $\mathrm{I}$ & $\mathrm{I}$ & $\mathrm{I}$ & $\mathrm{I}$ \\
\hline & \multicolumn{14}{|c|}{ Panel D: Silver } \\
\hline Asian & 175 & 9 & 0.755 & 0.953 & 1.266 & 1.481 & 0.82 & 0.862 & 0.648 & 0.618 & $\mathrm{I}$ & $\mathrm{I}$ & $\mathrm{I}$ & $\mathrm{I}$ \\
\hline Dotcom & 697 & 9 & $353.3 a$ & $393.7 \mathrm{a}$ & $394.97 \mathrm{a}$ & $394.03 \mathrm{a}$ & 0.858 & 1.219 & 1.03 & 0.912 & $\mathrm{D}$ & $\mathrm{D}$ & $\mathrm{D}$ & $\mathrm{D}$ \\
\hline ESDC & 805 & 1 & $80.10 a$ & $89.50 \mathrm{a}$ & $109.87 \mathrm{a}$ & $116.32 \mathrm{a}$ & $4.714 \mathrm{a}$ & $2.039 \mathrm{a}$ & $1.869 \mathrm{a}$ & $1.613 \mathrm{a}$ & $\mathrm{D}$ & $\mathrm{D}$ & $\mathrm{D}$ & $\mathrm{D}$ \\
\hline GFC & 522 & 3 & $46.4 \mathrm{a}$ & $54.53 \mathrm{a}$ & $59.048 \mathrm{a}$ & $61.53 \mathrm{a}$ & 1.09 & $1.306 \mathrm{c}$ & $1.889 \mathrm{a}$ & $1.667 \mathrm{a}$ & $\mathrm{D}$ & $\mathrm{D}$ & $\mathrm{D}$ & $\mathrm{D}$ \\
\hline
\end{tabular}

The behavior of returns of Gold index then reverses and becomes predictable (indication of market inefficiency) during European Sovereign Debt and Global financial crises thus supporting AMH. The behavior of returns from Metal and oil indices swings similar to Gold index at both the Engle LM and Mecleod li test, while Tsay test reveals different results as returns from Metal index are unpredictable during Asian crisis and the behavior swings and returns are predictable during Dotcom, European Sovereign Debt and Global financial crises periods. Returns from Oil index remain predictable during Asian crisis, then unpredictable during Dotcom crisis and finally again predictable during European Sovereign Debt and Global financial crises thus supporting AMH. Engle LM and McLeod Li tests reveal similar results for returns from Silver index as returns remain unpredictable during Asian crisis and the behavior swings and returns are predictable during Dotcom, European Sovereign Debt and Global financial crises periods. Tsay test reveals that Silver index exhibits insignificant nonlinear dependence (indication of market efficiency) during Asian and Dotcom crises. The behavior of returns of Silver index then reverses and becomes predictable (indication of market inefficiency) during European Sovereign Debt and Global financial crises thus supporting AMH.

BDS test revels that returns from Gold index remain predictable (nonlinear dependency/market inefficiency) during Asian crisis, then unpredictable (no nonlinear dependency/market efficiency) during Dotcom crisis and finally again predictable during European Sovereign Debt and Global financial crises thus supporting AMH. Metal and Oil indices produce similar results as returns are unpredictable supporting market efficiency during Asian and Dotcom crises. The behavior then shifts to significant predictability and market becomes inefficient during European Sovereign Debt and Global financial crises as the BDS test exhibits significant coefficients at 1\%. Silver index shows similar behavior at BDS test as it does with Engle LM and McLeod Li test, thus supporting AMH. Table 5 results of BDS test to identify nonlinearity trends in residuals of AR filtered returns. 1st and 2nd rows presents dimensions and embedded dimensions respectively in sub and the full-samples for the commodities (Gold, Metal, Oil \& Silver). ). Where "a" depicts $1 \%$ level of significance, while " $b$ " represents $5 \%$ and "c" shows $10 \%$.

Table 5

\begin{tabular}{|l|l|l|l|l|l|l|l|}
\hline BDS Test & \multicolumn{2}{l|}{$0.5 \sigma$} & $1 \sigma$ & $1.5 \sigma$ & $2 \sigma$ \\
\hline Dimensions & Observations & AR & & & \\
\hline Embedded Dimensions & & & \\
\cline { 1 - 5 } Sample Period & 175 & 6 & $1.9072 \mathrm{C}$ & $2.9294 \mathrm{a}$ & $3.8516 \mathrm{a}$ & $5.0079 \mathrm{a}$ \\
\hline Panel A: Gold & 697 & 10 & 0.1799 & 0.4411 & 0.7727 & 1.3848 \\
\hline Asian &
\end{tabular}


Review of Economics and Development Studies, Vol. 6 (1) 2020,

$67-81$

\begin{tabular}{|c|c|c|c|c|c|c|}
\hline ESDC & 805 & 1 & $2.9337 \mathrm{a}$ & $2.498 \mathrm{a}$ & $3.1004 \mathrm{a}$ & $3.6758 \mathrm{a}$ \\
\hline GFC & 522 & 1 & $3.8625 \mathrm{a}$ & $5.0007 \mathrm{a}$ & $5.796 \mathrm{a}$ & $3.293 \mathrm{a}$ \\
\hline \multicolumn{7}{|c|}{ Panel B: Metal } \\
\hline Asian & 175 & 1 & 1.6141 & 1.3513 & 1.1922 & $2.7834 \mathrm{a}$ \\
\hline Dotcom & 697 & 2 & 0.4906 & 0.6649 & 0.9861 & $1.8603 \mathrm{C}$ \\
\hline ESDC & 805 & 1 & $3.0645 \mathrm{a}$ & $2.55 \mathrm{a}$ & $3.0976 \mathrm{a}$ & $3.6853 \mathrm{a}$ \\
\hline GFC & 522 & 4 & $3.5922 \mathrm{a}$ & $4.5524 \mathrm{a}$ & $5 \cdot 3114 \mathrm{a}$ & $2.8264 \mathrm{a}$ \\
\hline \multicolumn{7}{|c|}{ Panel C: Oil } \\
\hline Asian & 175 & 7 & $1.8265 \mathrm{c}$ & 1.3452 & 1.3186 & 1.305 \\
\hline Dotcom & 697 & 5 & $1.9092 \mathrm{C}$ & 1.3355 & 1.202 & 0.8125 \\
\hline ESDC & 805 & 1 & $3.1542 \mathrm{a}$ & $4.3455 \mathrm{a}$ & $5.1279 \mathrm{a}$ & $5.1478 \mathrm{a}$ \\
\hline GFC & 522 & 1 & $4.691 \mathrm{a}$ & $7.0698 \mathrm{a}$ & $8.9094 \mathrm{a}$ & $10.8188 \mathrm{a}$ \\
\hline \multicolumn{7}{|c|}{ Panel D: Silver } \\
\hline Asian & 175 & 9 & 0.6124 & 1.0013 & 0.9354 & $1.8713 \mathrm{C}$ \\
\hline Dotcom & 697 & 9 & $2.8601 \mathrm{a}$ & $4.1803 \mathrm{a}$ & $5.1073 \mathrm{a}$ & $1.9701 \mathrm{a}$ \\
\hline ESDC & 805 & 1 & $4.8074 a$ & $5.6509 \mathrm{a}$ & $6.1529 \mathrm{a}$ & $6.4828 \mathrm{a}$ \\
\hline GFC & 522 & 3 & $4.467 \mathrm{a}$ & $4.8118 \mathrm{a}$ & $5.0899 \mathrm{a}$ & 5.8258 \\
\hline
\end{tabular}

\section{Findings and Conclusions}

Financial assets in global financial markets are attracting greater attention from practitioners as well as from researchers (Abdelsalam \& El-Komi, 2015). Varying degree of return predictability and informational efficiency are the fundamental questions and these are not adequately addressed in the existing literature. Thus we investigate in this paper the informational efficiency of four commodity indices in association with time varying AMH (Adaptive Market Hypothesis) of (Lo, 2004 \& 2005). Extensive analysis is conducted in this paper to answer key question that how predictability of commodity's return evolves with the passage of time using disaggregated data sets through linear and nonlinear econometric methods. For testing informational efficiency and degree of predictability of returns, both linear and nonlinear tests offer a sensible measure. We find commodities show time varying return predictability over time through sub-samples (crises periods) which is consistent with $\mathrm{AMH}$. Autocorrelation test (table 2) provides AMH consistent evidence by showing returns from all the commodities have gone through episodes of predictability (dependency/market inefficiency) and unpredictability (independency/market efficiency). The non-parametric runs test (table-2) provides similar results except Oil index returns which remains unpredictable supporting EMH throughout the sub-sample periods. All the commodity indices remain predictable (linear dependency) in all the subperiods of crisis at Variance ratio test (table 3) contradicting EMH. Results of nonlinear tests (BDS, Engle LM test, McLeod Li test and Tsay test see table $4 \& 5$ ) are evident that all the commodity indices returns show strong nonlinear dependence (market inefficiency) in some crises periods and while other show strong evidence of no non nonlinear dependence (market efficiency) and these findings are thus aligned and consistent with the inferences of AMH. In summary, the commodity returns are evident of time varying behavior as returns from commodities have swing through significant predictability (dependency) and insignificant predictability (independency) in sub-sets of crisis. The evolving evidence of commodity returns is casting a serious doubt to EMH while consistent with the implications of $\mathrm{AMH}$. Therefore, $\mathrm{AMH}$ is the best description of commodities returns.

This paper has attempted to provide a comprehensive and detailed analysis of the issue underpinning the research. But like any other research articles, this paper also has a number of 
limitations. The selection of sample size is the first limitation of the study. We did not include any era except crises periods. Secondly, we investigated only few popular commodities having active trading so, we excluded other commodities. Therefore, the results are generalized only to data for a sub-set of commodities. Thirdly, the paper ignored transaction cost (commissions, fee and taxes). The decision to overlook transaction cost was made on the basis of the fact that transaction costs are very freely negotiated between the clients and members. Fourth, a limited number of studies investigates the varying degree of market efficiency through AMH. So, the more literature could have been better suitable and to have a comprehensive view of behavior of commodity returns.

As Lo (2004) develops the notion of AMH in 2004, so future work on AMH is potentially plentiful. The use of rolling window analysis and larger full and sub-sample may be fruitful to examine $\mathrm{AMH}$. Thus, we recommend that a large sub-set of commodities and most recently listed commodities on NYSE may be used to examine this issue in future work. Future work may use qualitative research strategy along with quantitative strategy e.g. future studies may conduct interviews with participants of commodities market (brokers, investors \& regulators) to analyze their views about commodity price regularities with regards to different calendar anomalies and to investigate the role of investor behavior or sentiments in New York stock exchange. Researchers in future may extend this topic by analyzing technical rules, buy-hold strategy and other trading strategies to explore whether investors truly beat the market. The future work may use individual commodities, bond markets, foreign exchange markets and other equity markets around the globe to examine the changing levels of efficiency of markets. Researchers in future may compare markets from developed and developing countries through AMH to test whether the power of anomalies has changed (increased or decreased) over time. Furthermore; limited studies have covered impact of political regimes on stock market in the world and fewer in NYSE. Thus the future studies may include political factors such as overall country situation, political environment, government policies and economic factors to test whether these factors have positive or negative impacts on NYSE.

\section{References}

Abdelsalam, O., \& El-Komi, M. (2015). Corrigendum to “Islamic Finance: An Introduction”. Journal of Economic Behavior \& Organization, 116(C), 555-555.

Adrangi, B., \& Chatrath, A. (2003). Non-Linear dynamics in futures prices: Evidence from the Coffee, Sugar and Cocoa Exchange. Applied Financial Economics, 13(4), 245-256.

Ahti, V. (2009). Forecasting Commodity Prices with nonlinear Models.

Alagidede, P. (2011). Return behaviour in Africa's emerging equity markets. The Quarterly Review of Economics and Finance, 51(2), 133-140.

Alharbi, A. M. (2009). Nonlinearity and Market Efficiency in GCC Stock Makets. Doctoral Thesis.

Alvarez-Ramirez, J., Rodriguez, E., \& Eapinosa-Paredes, G. (2012). Is the US stock Market Becoming weakly Efficient over Time? Evidence from 8o-year-Long Data. Physica A: Statistical Mechanics and its Applications, 391(22), 5643-5647.

Amini, S., Hudson, R., \& Keasey, K. (2010). Stock return predictability despite low autocorrelation. Economics Letters, 108(1), 101-103.

Aradhyula, S. V., \& Holt, M. T. (1988). GARCH time-series models: An Application to retail livestock prices. Western Journal of Agriculture Economics, 13(2), 365-374.

Benavides, G. (2004). Price Volatility Forecasts for Agricultural Commodities: An Application of Historical volatility models, option implieds and composite approaches for futures prices of corn and wheat. Journal of Management, Finance and Economics, 3(2), 40-59.

Bollerslev, T. (1986). Generalized Autoregressive Conditional Heteroskedasticity. Journal of Econometrics, 31, 307-327. 
Brock, W. A., Scheinkman, J. A., LeBaron, B., \& Dechert, W. D. (1996). A Test for Independence Based on the Correlation Dimention. Econometric Reviews, 15(3), 197-235.

Caraiani, p. (2012). Nonlinear dynamics in CEE stock markets indices. Economics Letters, 114(3), 329331.

Charles, A., Darne, O., \& Kim, J. H. (2011). Small Sample Properties of Alternative Tests for Martingale Difference Hypothesis. Economics Letters, 110(2), 151-154.

Charles, A., Darne, O., \& Kim, J. H. (2012). Exchange-Rate Predictability and Adaptive Market Hypothesis: Evidence from Major Exchange Rates. Journal of International Money and Finance, 31(6), 1607-1626.

Engle, R. F. (1982). Autoregressive Conditional Heteroskedasticity with Estimates of the Variance of United Kingdom Inflation. Econometrica, 50(4), 987-1008.

Fama, E. F. (1965). The Behaviour of Stock Market Prices. Journal of Business, 38(1), 34-105.

Fama, F. E. (1970). Efficient Capital Markets: A review of Theory and Empirical Work. Journal of Finance, 25(2), 383-417.

Ghazani, M. M., \& Araghi, M. K. (2014). Evaluation of the Adaptive Market Hypothesis as an Evolutionary Perspective on Market Efficiency: Evidence from the Tehran Stock Exchange. Research in International Business and Finance, 32, 50-59.

Granger, W. C., \& Anderson, A. P. (1978). An Introduction to Bilinear Time Series model. Vandenhoeck and Ruprecht: Guttingen.

Hiremath, G. S., \& Kamaiah, B. (2010). Nonlinear dependence in stock returns:Evidence from India. Journal of Quantitative Economics, 8(1), 69-85.

Hiremath, G. S., \& Kumari, J. (2014). Stock Returns Predictability and the Adaptive Market Hypothesis in Emerging Markets: Evidence from India. Springer Plus, 3-14.

Ho, C. S.-F., Abd-Rehman, N. A., Yusuf, N. H.-M., \& Zamzamin, Z. (2014). Performance of Global Islamic versus Conventional Share Indices: International Evidence. Pacific-Basin Finance Journal, 28, 110-121.

Ito, M., \& Sugiyama, S. (2009). Measuring the Degree of Time Varying Market Inefficiency. Economics Letters, 103(1), 62-64.

Ito, M., Noda, A., \& Wada, T. (2016). The Evolution of Stock Market Efficiency in the US: A NonBayesian Time Varying Model Approach. Applied Economics, 48(7), 621-635.

Jawadi, F., Jawadi, N., \& Louhichi, W. (2014). Conventional and Islamic stock price performance: An Empirical Investigation. International Economics, 137, 73-87.

Karali, B., \& Power, G. (2009). What Explains High Commodity Price Volatility? Estimating a Unified Model of Common and Commodity-Specific, High and Low Frequency Factors. 2009 Annual Meeting Agricultural, (pp. July 26-28, 2009). Milwaukee, Wisconsin.

Keenan, D. M. (1985). A Tukey Nonadditivity-type Test for Time Series Nonlinearity. Biometrika, 72(1), 39-44.

Kim, J. H., \& Shamsuddin, A. (2008). Are Asian Stock Markets Efficient? Evidence from new Multiple Variance Ratio Test. Journal of Empirical Finance, 15(3), 518-532.

Kim, J. H., Shamsuddin, A., \& Lim, K. P. (2011). Stock Return Prdictability and the Adaptive Market Hypothesis: Evidence from Century Long US data. Journal of Empirical Finance, 18(5), 868-879.

Lim, K. P., Brooks, R. D., \& Hinich, M. J. (2008). Nonlinear Serial Dependence and the Weak-Form Efficiency of Asian Emerging Markets. Journal of International Financial Markets, Institutions and Money, 18(5), 527-544.

Lim, K. P., Luo, W., \& Kim, J. (2013). Are US Stock Index Returns Predictable? Evidence from Automatic Autocorrelation-Based Tests. Applied Economics, 45(8), 953-962.

Lim, K.-p., \& Hooy, C.-W. (2013). Non-linear predictability in G7 stock index returns. The Manchester School, 81(4), 620-637. 
Lo, A. W. (2004). The Adaptive Market Hypothesis. Journal of Portfolio Management, 30, 15-29.

Lo, A. W. (2005). Reconciling Efficient Markets with Behavioral Finance: The Adaptive Market Hypothesis. Journal of Investment Consulting, 7(2), 21-44.

Lo, A. W., \& MacKinlay, C. A. (1988). Stock Market Prices do not Follow Random Walks: Evidence from a Simple Specification Test. The Review of Financial Studies, 1(1), 41-66.

McLeod, A. I., \& Li, W. K. (1983). Diagnostic checking ARMA time series models using squared-residual autocorrelations. Journal of Time Series Analysis, 4, 269-273.

Milas, C., \& Otero, J. (2002). Smooth Transition Vector error Correction Models for the Spot Prices of Coffee. Applied Economics Journal, 14, 925-928.

Neely, C. J., Weller, P. A., \& Ulrich, J. M. (2009). The Adaptive Markets Hypothesis: Evidence from the Foreign Exchange Market. Journal of Financial and Quantitative Analysis, 44 (2), 467-488.

Noda, A. (2012). A Test of the Adaptive Market Hypothesis using Non-Bayesian Time-Varying AR Model in Japan. Financial Research Letter.

Noda, A. (2016). A test of Adaptive Market Hypothesis Using a Time Varying AR Model in Japan. Finance Research Letters, 17, 66-71.

Patterson, D., \& Ashley, R. A. (2000). A Nonlinear Time Series Workshop: A Toolkit for Detecting and Identifying Nonlinear Serial Dependence. Boston, MA: Kluwer Academic.

Ramirez, S. C., Arellano, P. L., \& Rojas, O. (2015). Adaptive Market Efficiency of Agricultural Commodity Future Contracts. Contraduria Administracion, 6o, 389-401.

Rodriguez, E., Aguilar-Cornejo, M., Femat, R., \& Alvarez-Ramirez, J. (2014). US Stock Market Efficiency over Weekly, Monthly, Quarterly and Yearly Time Scales. Physica A: Statistical Mechanics and its Applications, 413, 554-564.

Sensory, A., Aras, G., \& Hacihasanoglu, E. (2015). Predictability Dynamics of Islamic and Conventional Equity Markets. The North American Journal of Economics and Finance, 31, 222-248.

Smith, G. (2012). The Changing and Reletive Efficiency of European Emerging Stock Markets. European Journal of Finance, 18(8), 689-708.

Tansuchat, R., Chang, C.-L., \& McAleer, M. (2009). Modelling Long Memory Volatility in Agricultural Commodity Future Returns. CARF-F-183 Series, Center for Advanced Research in Finance. Faculty of Economics, University of Tokyo.

Tejeda, H. A., \& Goodwin, B. K. (2009). Price volatility, nonlinearity, and asymmetric adjustments in corn, soybean, and cattle markets: Implications of ethanol-driven (market) shocks. In NCCC-134 Conference on Applied Commodity Price Analysis, Forecasting, and Market Risk Management. St. Louis: Missouri.

Todea, A., Ulici, M., \& Silaghi, s. (2009). Adaptive Market Hypotheis; Evidence Asia Pacific Financial Markets. The review of Finance And Banking, 1(1), 7-13.

Tsay, R. S. (1986). Nonlinearity tests for time series. Biom, 73, 461-466.

Urquhart, A. (2013). An Empirical Analysis of the Adaptive Market Hypothesis and Investor Sentiment in Extreme Circumstances. PhD Thesis.

Urquhart, A., \& Hudson, R. (2013). Efficient or Adaptive Markets? Evidence from Major Stock Markets using very Long-Run Historic Data. International Review of Financial Analysis, 28, 130-142.

Urquhart, A., Gebka, B., \& Hudson, R. (2015). How Exactly do Market Adapt? Evidence from the Moving Average Rule in Three Developed Markets. Journal of International Financial Markets, Institutions and Money, 38, 127-147.

Wald, A., \& Wolfowitz, J. (1940). On a test Whether two Samples are form the same Population. The Annals of Mathematical Statistics, 11(2), 147-162. 